\title{
The association between infant and young child feeding practices and diarrhoea in Tanzanian children
}

\author{
Felix Akpojene Ogbo ${ }^{1,2^{*}}$, Hillary Nguyen ${ }^{1}$, Sabrina Naz ${ }^{1}$, Kingsley E. Agho ${ }^{1}$ and Andrew Page ${ }^{1}$
}

\begin{abstract}
Background: Diarrhoea is a leading cause of child mortality in Tanzania. The association between optimal infant feeding practices and diarrhoea has been reported elsewhere, but the evidence has been limited to promote and advocate for strategic interventions in Tanzania. This study examined the association between infant and young child feeding (IYCF) practices and diarrhoea in Tanzanian children under 24 months.
\end{abstract}

Methods: The study used the Tanzania Demographic and Health Survey data to estimate the prevalence of diarrhoea stratified by IYCF practices. Using multivariable logistic regression modelling that adjusted for confounding factors and cluster variability, the association between IYCF practices and diarrhoea among Tanzanian children was investigated.

Results: Diarrhoea prevalence was lower in infants aged 0-5 months whose mothers engaged in exclusive breastfeeding (EBF) and predominant breastfeeding (PBF) compared to those who were not exclusively and predominantly breastfed. Infants aged 6-8 months who were introduced to complementary foods had a higher prevalence of diarrhoea compared to those who received no complementary foods, that is, infants who were exclusively breastfed at 6-8 months. Infants who were exclusively and predominantly breastfed were less likely to experience diarrhoea compared to those who were not exclusively and predominantly breastfed [adjusted odds ratio (AOR) $0.31,95 \%$ confidence interval (CI) $0.16-0.59, P<0.001$ for $E B F$ and $A O R=0.30,95 \% \mathrm{Cl} 0.10-0.89, P=0.031$ for PBF]. In contrast, infants aged 6-8 months who were introduced to complementary foods were more likely to experience diarrhoea compared to those who received no complementary foods $(\mathrm{AOR}=2.91,95 \% \mathrm{Cl} 1.99-4.27, P<0.001)$.

Conclusions: The study suggests that EBF and PBF were protective against diarrhoeal illness in Tanzanian children, while the introduction of complementary foods was associated with the onset of diarrhoea. Strengthening IYCF (facility- and community-based) programmes would help to improve feeding behaviours of Tanzanian women and reduce diarrhoea burden in children under 2 years.

Keywords: Breastfeeding, Diarrhoea, Complementary feeding, Children, Tanzania

\section{Background}

The early childhood period is considered one of the most important phases of life, determining the quality of health, behaviour and well-being across the lifespan [1]. The early year period also reflects a time of high vulnerability of the child to various adverse health outcomes such as diarrhoea [2]. In the past two decades, significant progress has been made in reducing diarrhoeal

\footnotetext{
* Correspondence: felgbo@yahoo.co.uk; f.ogbo@westernsydney.edu.au

${ }^{1}$ Translational Health Research Institute, School of Medicine, Western Sydney University, Campbelltown Campus, Locked Bag 1797, Penrith, NSW 2571,

Australia

${ }^{2}$ Prescot Specialist Medical Centre, Makurdi, Benue State, Nigeria
}

morbidity and mortality among children under 5 years old; however, recent reports have shown that diarrhoea is still a leading cause of under-five mortality in many developing countries [3, 4]. In sub-Saharan African (SSA) countries, including Tanzania, children are likely to die before their fifth birthday from illnesses such as diarrhoea and upper respiratory tract infection compared to their counterparts in developed countries [5-7]. Additionally, under-five deaths in developing countries are mainly attributable to preventable infectious diseases (including diarrhoea) in which appropriate breastfeeding, improved 
water and sanitation, routine vaccination programs and strong operational policies can play significant roles $[8,9]$.

Optimal breastfeeding practices protect children against diarrhoea-related diseases [10, 11], and mothers who optimally breastfeed their babies have been shown to have a reduced risk of type 2 diabetes mellitus and breast and ovarian cancers $[5,12]$. A recent review indicated that only approximately $40 \%$ of infants aged 0-5 months in SSA countries were exclusively breastfed, reflecting gaps in optimal infant feeding practices in many communities [5]. The study also suggested that many infants were introduced to complementary foods too early in SSA countries. While the introduction of complementary foods to infants is crucial for infant growth and development, previous studies have indicated that the poor conditions in which those foods are prepared, stored or fed to the child as well as the immunological status of the child may contribute to the onset of diarrhoea [13-17]. Previous reports from Tanzania have indicated that the prevalence of exclusive breastfeeding (EBF) and continued breastfeeding at 1 year was high (50 and 92\%, respectively) [18], and the median duration of any breastfeeding was 21 months, suggesting that some mothers exclusively breastfed for more than 6 months [19]. Nonetheless, the relationship between $\mathrm{EBF}$ and continued breastfeeding at 1 year and diarrhoea has not been investigated in Tanzania.

In 2016, the global burden of disease study indicated that diarrhoeal diseases contributed to the burden of under-five deaths and disabilities, which accounted for $5.4 \%$ of the total deaths and $5.9 \%$ of disability-adjusted life years in Tanzania [20, 21]. Additionally, the prevalence of diarrhoea among children under 5 years varied from 6\% [22] to 22\% [23] in Tanzania. Studies that investigated the impact of infant feeding practices on diarrhoea in SSA (e.g. Nigeria [10]) and Asia (e.g. Vietnam [24] and Bangladesh [7]) have been published, where EBF was protective against diarrhoeal illness. However, evidence on the association between infant and young child feeding (IYCF) practices and diarrhoea has been limited in Tanzania [25], where studies have primarily focused on HIV-exposed infants [26, 27].

A country-specific study that is focused on the relationship between IYCF practices and diarrhoea would be essential to public health experts to promote and advocate for strategic investments in IYCF programmes to improve child health outcomes in Tanzania. Additionally, public health programmes are largely funded by international agencies in Tanzania [28], and findings from this study will also be of interest internationally, particularly in the context of the renewed focus on child nutrition agenda at the global, regional and national levels [29]. The present study aimed to investigate the association between IYCF practices (i.e. EBF; early/timely initiation of breastfeeding; predominant breastfeeding; timely introduction of solid, semi-solid and soft foods and continued breastfeeding at 1 year) and diarrhoea in Tanzanian children under 24 months.

\section{Methods}

\section{Data sources}

The study used the Tanzania Demographic and Health Survey (TDHS, 2010) data, collected by the National Bureau of Statistics, Dar es Salaam, Tanzania, with technical assistance from the Inner City Fund (ICF) International, Maryland, USA. The TDHS collects maternal and child information that includes socio-demographics, child and female reproductive characteristics, obtained from a nationally representative sample of households. Using standardised face-to-face questionnaires, the TDHS collected information on IYCF practices from eligible women of childbearing age (15-49 years). For the IYCF practices, questions in the survey tool included information on breastfeeding and complementary feeding practices, as well as duration and diversity of the infant food provided. A weighted total sample of 10,139 eligible women were interviewed, yielding 96\% response rate. Additional information on the data source (including sampling procedure and methodology for data collection) is described elsewhere $[19,30]$.

\section{Outcome variable}

The study outcome was diarrhoea, defined as the passage of three or more loose or liquid stools per day, and was based on maternal recall of each child under 5 years of age in the household during the 2 weeks preceding the survey. Consistent with previous studies $[18,31]$, this analysis used information from the most recent live birth, aged less than 24 months, living with the respondent to reduce recall bias. Measurement of diarrhoea was based on the child age group for each IYCF practice [10].

\section{Exposure variables}

The exposure variables for this study were the IYCF indicators, assessed based on the World Health Organization (WHO) definitions for assessing IYCF practices [32]:

- Early or timely initiation of breastfeeding: the proportion of children 0-23 months of age who were put to the breast within $1 \mathrm{~h}$ of birth.

- Exclusive breastfeeding: the proportion of infants 0-5 months of age who received breast milk as the only source of nourishment but allowed oral rehydration solution, drops or syrups of vitamins and medicines.

- Predominant breastfeeding: the proportion of infants 0-5 months of age who received breast milk as the main source of nourishment but allows water, 
water-based drinks, fruit juice, oral rehydration solution, drops or syrups of vitamins and medicines.

- Continued breastfeeding at 1 year: the proportion of children 12-15 months of age who were fed breast milk.

- Bottle feeding: the proportion of infants 0-23 months of age who received any liquid (including breast milk) or semi-solid food from a bottle with nipple/teat.

- Introduction of solid, semi-solid and soft foods: the proportion of infants 6-8 months of age who received solid, semi-solid or soft foods.

Early initiation of breastfeeding and EBF were incorporated into the analyses because of their association with reduced morbidity among children under 5 years [33, 34]. Predominant breastfeeding, bottle feeding, continued breastfeeding at 1 year and the introduction of solid, semi-solid and soft foods were included due to their effect on the increased risk of diarrhoeal morbidity and mortality among children under 5 years [10, 35-37].

A number of potential confounding variables were considered in the analyses based on previous studies [10, 24] and data availability. These variables were categorised as socioeconomic factors (mother's employment, maternal education and household wealth), health service factor (frequency of antenatal care visit), individual factors (maternal age, child age and gender), and household factors (urban or rural, drinking water source and type of toilet facility). A detailed description of these variables is provided in Table 1. The household wealth index was calculated as a score of household assets (such as ownership of transportation devices, ownership of durable goods and household facilities), which was derived from a principal component analysis conducted by the National Bureau of Statistics, Dar es Salaam, Tanzania, and ICF International [19].

Source of drinking water was categorised as 'Improved' and 'Not improved'. Improved drinking water source included residences where water was piped into the dwelling-yard, access to a public tap or standpipe, a tube well or borehole, protected well, protected spring, rainwater and/or bottled water. Not improved water source comprised access to an unprotected well, unprotected spring, tanker truck or cart with a drum, surface water, sachet water and/or another source [38].

Type of toilet was categorised as 'Improved' and Not improved'. Improved type of toilet included toilets such as flush or pour-flush toilets or piped to the sewer system, septic tank, and pit latrine; flush or pour-flush to septic tank; flush or pour flush to pit latrine; ventilated improved pit latrine; pit latrine with slab and/or compositing toilet. Not improved toilets comprised flush or pour-flush but not piped to sewer, septic tank or pit latrine; pit latrine without a slab or open pit; bucket or hanging toilet and no toilet facility or the use of bush or field [38].
Table 1 Characteristics of the study population

\begin{tabular}{lll}
\hline Characteristics & $N$ & $\begin{array}{l}\%(95 \% \text { confiden } \\
\text { interval) }\end{array}$ \\
\hline $\begin{array}{l}\text { Socioeconomic } \\
\text { Mother's employment }\end{array}$ & & \\
$\quad$ Not working & 490 & $14.5(12.7-16.4)$ \\
$\quad$ Working & 2902 & $85.5(83.6-87.3)$ \\
Mother's education & & \\
$\quad$ No schooling & 865 & $25.5(22.7-28.5)$ \\
$\quad$ Primary education & 2278 & $67.2(64.4-69.8)$ \\
$\quad$ Secondary and higher education & 249 & $7.3(6.1-8.8)$ \\
Household wealth & & \\
$\begin{array}{l}\text { Poor } \\
\text { Middle }\end{array}$ & 1536 & $45.3(41.7-49.0)$ \\
Rich & 1360 & $40.1(37.1-43.2)$ \\
& 496 & $14.6(12.1-17.7)$
\end{tabular}

Health Service

Antenatal visits

$<1$

$13.5(12.0-15.3)$

$2-3$

2280

$71.5(69.4-73.5)$

$4+$

478

$15(13.2-17.0)$

Individual

Mother's age (years)

$15-24$

25-34

$35-49$

$37.8(35.5-40.1)$

$42.8(40.8-44.9)$

$17.6(17.6-21.4)$

Sex of child

Male

$50.4(48.5-52.2)$

Female

$49.6(47.8-51.5)$

Child age (months)

0-3

17.3 (16.0-18.8)

4-5

26.5 (24.5-28.6)

6-11

$26.6(24.61-28.8)$

12-17

$4.3(3.5-5.2)$

18-23

$25.3(23.6-17.4)$

Household

Household location

Urban

707

$20.8(16.7-25.7)$

Rural

2685

79.2 (74.3-83.3)

Source of drinking water

Not improved

$70.9(67.0-74.6)$

Improved

$29.0(25.4-32.9)$

Type of toilet

Not improved

6697

$84.9(82.5-87.2)$

Improved

1183

$15.0(12.8-17.5)$

$N$ weighted sample size 


\section{Statistical analysis}

The exposures were expressed as dichotomous variables, where respondents (women aged 15-49 years) who exclusively breastfed were coded as ' 1 ' and those who did not were coded as ' 0 '. The same analytical approach was employed for other IYCF indicators. Preliminary analyses involved frequency tabulations of confounding variables (i.e. socioeconomic, health service, individual and household factors) in the TDHS, followed by an estimation of the prevalence of IYCF indicators, as well as a combination of IYCF practices and diarrhoea (and their corresponding $95 \%$ confidence intervals).

Univariable and multivariable logistic regression analyses were used to investigate the associations between IYCF practices and diarrhoea, adjusted for potential confounders. Regression models were restricted to the youngest living child aged $<24$ months living with the respondent (women aged 15-49 years) to reduce recall bias. Prevalence estimates were calculated with the 'svy' function used to allow for adjustments for the cluster sampling design and regression modelling using the 'xlogit' function. All analyses were performed in Stata software version 14.0 (Stata Corporation, College Station, TX, USA).

\section{Ethics}

Measure DHS/ICF International obtained ethical approval from the Medical Research Coordinating Committee (MRCC), the national health research coordinating body in Tanzania. All questionnaires used for the DHS were reviewed and approved by ICF International Institutional Review Board (IRB) to ensure they met the US Department of Health and Human Services regulations for the protection of human participants as well as the host country's IRB, to ensure compliance with national laws. The datasets used are available to apply for online, and approval was obtained from Measure DHS/ICF International for the analysis.

\section{Results}

Of the mothers surveyed $(N=10,139), 43.4 \%$ initiated breastfeeding within the first hour of birth and $48.6 \%$ exclusively breastfed for the first 6 months of their infants' life (Table 2). Only $10.1 \%$ of infants aged $0-5$ months were predominantly breastfed, while $3.7 \%$ were bottle-fed. Many infants aged 6-8 months were introduced to complementary foods $(72.2 \%)$, while the majority of mothers continued breastfeeding at 1 year (89.6\%).

When examining IYCF indicators in relation to the prevalence of diarrhoea, infants under 6 months of age who were exclusively and predominantly breastfed had a lower prevalence of diarrhoea compared to their counterparts who were not exclusively and predominantly breastfed (Table 2). In contrast, children aged 1215 months who continued breastfeeding at 1 year had a
Table 2 Prevalence of IYCF indicators and diarrhoea among children 0-23 months in Tanzania, TDHS 2010

\begin{tabular}{lll}
\hline$N^{*}$ & $\begin{array}{l}\text { Prevalence of IYCF } \\
\text { indicators \% }(95 \% \mathrm{Cl})^{\mathrm{a}}\end{array}$ & $\begin{array}{l}\text { Prevalence of } \\
\text { diarrhoea \% } \\
(95 \% \mathrm{Cl})^{\mathrm{b}}\end{array}$ \\
&
\end{tabular}

Early initiation of breastfeeding

$\begin{array}{llll}\text { No } & 1920 & 56.6(54.4,59.1) & 20.0(17.6,22.7) \\ \text { Yes } & 1472 & 43.4(40.9,46.0) & 20.2(17.6,23.1)\end{array}$

Exclusive breastfeeding

$\begin{array}{llll}\text { No } & 447 & 51.4(47.3,55.6) & 16.7(12.4,22.2) \\ \text { Yes } & 422 & 48.6(44.4,52.8) & 4.8(3.0,7.7)\end{array}$

Predominant breastfeeding

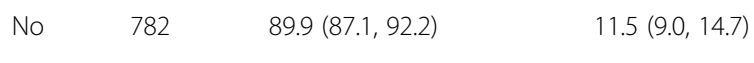

$\begin{array}{llll}\text { Yes } & 88 & 10.1(7.7,12.9) & 4.4(1.5,12.3)\end{array}$

Continued breastfeeding at 1 year

$\begin{array}{lll}\text { No } & 59.5 & 10.4(7.8,13.6)\end{array}$

$\begin{array}{lll}\text { Yes } \quad 515.2 \quad & 89.6(86.4,92.2) & 23.2(19.9,28.0)\end{array}$

Bottle feeding

$\begin{array}{llll}\text { No } & 3267 & 96.3(95.2,97.2) & 19.8(17.8,21.9)\end{array}$

$\begin{array}{llll}\text { Yes } & 125 & 3.7(2.8,4.7) & 26.6(17.8,37.9)\end{array}$

Introduction of solid, semi-solid and soft foods at 6-8 months

$\begin{array}{lll}\text { No } \quad 355 & 27.9(245.0,31.0) & 11.87(9.3,15.0)\end{array}$

$\begin{array}{llll}\text { Yes } & 920 & 72.2(69.0,75.0) & 25.82(20.2,32.4)\end{array}$

$N^{*}$ weighted total number of children aged 0-23 months for each IYCF indicator ${ }^{\text {a }}$ Prevalence represents the overall weighted proportion of children with diarrhoea for each level ('Yes', 'No') of IYCF indicators

'Prevalence represents the overall weighted proportion of children with diarrhoea for each level ('Yes', 'No') of infant and young child feeding indicators

higher prevalence of diarrhoea compared to their counterparts. Similarly, infants aged 6-8 months who were introduced to complementary foods had a higher prevalence of diarrhoea compared to those who received no complementary foods, that is, infants who were exclusively breastfed at 6-8 months. There was no difference in diarrhoea prevalence among children who were put to the breast within the first hour of birth and those who were not (Table 2).

Multivariable analyses revealed that infants aged $0-5$ months who were exclusively breastfed were less likely to experience diarrhoea compared to those who were not exclusively breastfed [adjusted odds ratio (AOR) 0.31, 95\% confidence interval (CI) $0.16-$ $0.59, P<0.001]$. Infants who were predominantly breastfed were significantly less likely to experience diarrhoea compared to those who were not predominantly breastfed (AOR $=0.30,95 \%$ CI $0.10-0.89, P=0.031$ ) [Table 3]. The analysis showed that infants who received solid, semi-solid and soft foods at age 6-8 months were approximately three times more likely to experience diarrhoea compared to their counterparts who received no complementary foods, that is, infants who were exclusively breastfed at 68 months (AOR $=2.91,95 \%$ CI 1.99-0.89, $P<0.001)$. Children 
Table 3 Association between diarrhoea and infant and young child feeding (IYCF) indicators in Tanzania, TDHS 2010

\begin{tabular}{|c|c|c|c|c|}
\hline IYCF indicators & $\begin{array}{l}\text { Unadjusted OR } \\
(95 \% \mathrm{Cl})\end{array}$ & $P$ value & $\begin{array}{l}{ }^{a} \text { Adjusted OR } \\
(95 \% \text { Cl) }\end{array}$ & $P$ value \\
\hline \multicolumn{5}{|c|}{ Early initiation of breastfeeding } \\
\hline No & 1.00 & & 1.00 & \\
\hline Yes & $0.97(0.79,1.18)$ & 0.749 & $1.00(0.81,1.25)$ & 0.959 \\
\hline \multicolumn{5}{|c|}{ Exclusive breastfeeding } \\
\hline No & 1.00 & & 1.00 & \\
\hline Yes & $0.33(0.18,0.59)$ & $<0.001$ & $0.31(0.16,0.59)$ & $<0.001$ \\
\hline \multicolumn{5}{|c|}{ Predominant breastfeeding } \\
\hline No & 1.00 & & 1.00 & \\
\hline Yes & $0.29(0.10,0.83)$ & 0.022 & $0.30(0.10,0.89)$ & 0.031 \\
\hline \multicolumn{5}{|c|}{ Continued breastfeeding at 1 year } \\
\hline No & 1.00 & & 1.00 & \\
\hline Yes & $1.12(0.42,2.97)$ & 0.820 & $1.24(0.42,3.64)$ & 0.692 \\
\hline \multicolumn{5}{|l|}{ Bottle feeding } \\
\hline No & 1.00 & & 1.00 & \\
\hline Yes & $1.16(0.73,1.84)$ & 0.509 & $1.36(0.81,2.29)$ & 0.251 \\
\hline \multicolumn{5}{|c|}{ Introduction of solid, semi-solid and soft foods at 6-8 months } \\
\hline No & 1.00 & & 1.00 & \\
\hline Yes & $2.87(1.98,4.14)$ & $<0.001$ & $2.91(1.99,4.27)$ & $<0.001$ \\
\hline
\end{tabular}

${ }^{a}$ Models adjusted for socioeconomic status (including maternal education, father's education, employment, household wealth), health service (antenatal care visits), household factors (household location, type of toilet and source of drinking water) and individual factors (maternal age, child's age, gender)

aged 12-15 months who continued breastfeeding at 1 year and those aged 0-23 months who were bottle-fed were more likely to experience diarrhoea, but these findings were not statistically significant (Table 3 ).

\section{Discussion}

The present study found that the prevalence of diarrhoea was lower among infants whose mothers engaged in EBF and predominant breastfeeding (PBF) practices. The prevalence of diarrhoea was higher in children who continued breastfeeding at 1 year compared to those who had ceased breastfeeding at the same age. Children who were bottle-fed had a higher prevalence of diarrhoea compared to those who were not bottle-fed. Similarly, the prevalence of diarrhoea was higher in infants aged 6-8 months who received complementary foods compared to those who did not, that is, infants who were exclusively breastfed at 6-8 months. Our analyses revealed that EBF and PBF were protective against diarrhoeal illness in Tanzanian children aged 0-5 months, after adjustment for confounding variables. In contrast, infants aged 6-8 months who received complementary foods were approximately three times more likely to experience diarrhoea compared to those who received no complementary foods.
The study showed that the prevalence of diarrhoea was higher among infants who were not exclusively breastfed. Also, the likelihood of an infant aged under 6 months to experience diarrhoea was higher among those not exclusively breastfed compared to those who were exclusively breastfed. This finding is consistent with evidence from other developing countries, including Bangladesh [7], Vietnam [24] and Nigeria [10], where EBF was protective of diarrhoeal illness among infants of the same age, even after adjusting for poor sanitation and unsafe drinking water source [10, 24]. Similarly, a meta-analysis of 18 studies also reported the protective effects of EBF in reducing the burden of diarrhoeal illness [6]. Reasons for the protective effect of EBF on diarrhoea are based on the fact that EBF limits the infant's exposure to contaminated liquids and foods, as well as the immunological activities of breast milk to protect the infant's gastrointestinal tract from invading micro-organisms [5, 17]. Additionally, studies have reported that breast milk also stimulates the innate immune system $[39,40]$ and epigenetic programme of the infant, activities which are also essential for the prevention of infections [41].

Our study suggested that PBF was protective against diarrhoea among Tanzanian children, and this was consistent with previous studies from Nigeria [10], Bangladesh [7] and other SSA countries with high diarrhoea mortality [25]. However, studies from developing countries (such as Ethiopia and Burkina Faso) have shown that PBF increased the likelihood of the infant to experience diarrhoea $[6,24,42-44]$ as parents or caregivers often insist that water-often 'unimproved' and a primary source of infection-induces suckling or quenches an infant's thirst after breastfeeding [45-47]. Although PBF has the potential to increase the likelihood of the infant to experience diarrhoea because of the introduction of food-based fluids, Rajiv and colleagues have argued that promoting both EBF and PBF may be more beneficial than promoting EBF over PBF. The authors also noted that there is limited evidence to differentiate the benefits of EBF from those of PBF [11]. Our analysis underscores the fact that both EBF and PBF may have similar impacts on diarrhoea prevention among children aged 0-5 months in Tanzania. Nevertheless, efforts must be made to promote EBF over PBF as the possibilities of water or water-based food contamination in Tanzania are high because of limited access to improved drinking water source, improved sanitation and high-quality food storage facilities for mothers from low SES group and those living in urban slums or rural areas [48].

The study showed that continued breastfeeding at 1 year and bottle feeding were associated with a higher likelihood of the infant to experience diarrhoea, but the relationship was not statistically significant. Previous 
studies reported that continued breastfeeding at 1 year and bottle feeding were associated with an increased likelihood of the child to experience diarrhoea [10, 25]. Importantly, the impact of continued breastfeeding and bottle feeding on diarrhoea could be attributed to the introduction of contaminated complementary food/water or use of a contaminated bottle with a teat or nipple given the age intervals used in assessing those indicators correspond to a time when the infant has commenced complementary foods [10, 43, 49]. Similarly, the WHO considers bottle feeding as a breastfeeding indicator because of the association between bottle feeding and increased diarrhoeal morbidity and mortality $[32,37]$.

The present study suggested that timely introduction of solid, semi-solid, and soft foods was associated with an increased likelihood of the infant to experience diarrhoea. Prior studies have shown that the introduction of complementary foods in many developing countries (including Tanzania) predisposes the infant to experience diarrhoea because of the unsafe conditions in which the foods are handled, prepared and stored $[14,50]$, and this may be the case in our study. In Tanzania, maize is the most commonly used complementary foods for infants, but maize and maize-based foods have been shown to contain a high concentration of fumonisin-a diarrhoea causing mycotoxin [51-53]. A number of locally relevant approaches have been suggested to limit the infants' exposure to high concentration of fumonisin-contaminated maize in Tanzania. These include maize sorting, dehulling of maize (removal of the hull from the seed) or limiting the daily intake of maize and/or replacing maize with other less fumonisin-contaminated cereal such as sorghum or finger millet [51]. However, there are significant challenges to the full implementation of those strategies. For example, resource constraint farmers are unwilling to sort out low-quality maize from their annual harvest $[54,55]$ or the household preference for the whole maize instead of the dehulled maize product [55]. Our finding implies that mothers should not only be encouraged to timely introduce complementary foods to their infants but also childhood nutrition intervention strategies must ensure that those foods are safe and nutritionally balanced, consistent with the WHO recommendation.

\section{Policy implications}

Our study has policy and practical implications for public health experts, decision-makers and researchers as it further highlights the important role of IYCF practices in the context of diarrhoeal disease in a developing country. Accordingly, facility-based interventions such as BabyFriendly Hospital Initiative (BFHI) to adequately promote and support optimal IYCF practices are essential to reduce diarrhoea burden. However, a report from Tanzania has shown that the BFHI is weak. That is, of the 3600 maternity service centres in the country, only 18 health facilities were certified baby friendly centres in 2015 [56], indicating that many health facilities and professionals may be unaware of the BFHI. This gap in the full implementation of the BFHI-shown to promote and support optimal IYCF behaviours [57-61] - suggests that more work is needed to improve breastfeeding behaviours of Tanzania mothers. Broadening the BFHI in Tanzania will not only improve EBF and reduce diarrhoea morbidity and mortality but could also increase household productivity due to a reduction in child sick days [5].

Furthermore, the World Breastfeeding Trends Initiative for Tanzania reported that the national-level policy framework and programme coordination to promote and support breastfeeding practices are 'adequate'. Nevertheless, the full implementation of breastfeeding programmes at the health facility and community levels, as well as linkages between breastfeeding programmes at the national and subnational levels, are fragile [56]. Interventions to improve IYCF practices and reduce diarrhoea burden in Tanzania should include improvement in IYCF information for health professionals at the health system level, strengthening the routine postnatal care follow-up for mothers (such as subsidised or free maternal health care services) and scaling up community-based strategies (such as Baby-Friendly Community Initiatives, BFCI, and reinforcing linkages between facility and communitybased programmes). Strengthening compliance with the Employment and Labour Relations Act 2004 and increasing domestic funding for IYCF programmes will also have impacts on breastfeeding practices [56, 62]. A detailed description of those facility- and community-based initiatives to improve IYCF behaviours in Tanzania has been noted elsewhere [56].

In 2016, the Government of the United Republic of Tanzania launched the National Multisectoral Nutrition Action Plan (NMNAP) for the years spanning 20162021, with the improvement of breastfeeding practices and the introduction of complementary foods being part of the rationale for this initiative [62]. Since the 1960s, Tanzania's commitment to improving childhood nutrition has been long-lasting. However, the issue has been to translate the government commitment into evidencebased interventions that are appropriately financed, wellimplemented and tracked [62]. To reduce the burden of diarrhoea associated with the introduction of complementary foods in Tanzania, a number of strategic approaches will be needed. These may include increased translation of government commitment to well-resourced and wellcoordinated, measurable and culturally appropriate initiatives, and collaborative efforts between government agencies (such as health, agriculture and education) [62] and industry partners [63] to reduce the contamination associated with complementary foods. Additionally, studies that investigate the nutritional status of children may 
be warranted to inform childhood nutrition initiatives and policies in Tanzania.

\section{Study limitations and strengths}

A number of methodological limitations should be considered. First, the study used cross-sectional data, and the establishment of a clear temporal association between IYCF and diarrhoea cannot be measured because the data were collected simultaneously. Second, the exposure and outcome variables were based on self-report, and this is a source of recall or measurement bias. The analysis may have overestimated or underestimated the association between IYCF practices and diarrhoea as the mother may have incorrectly reported the number of loose stools passed by the child. Nonetheless, our findings are consistent with previous evidence from developing countries on IYCF practices and diarrhoea [7, 10, 24]. Third, unmeasured confounding factors such as the impact of culture, and family structure and dynamics may be a limitation of the study. Fourth, data on the duration and severity of diarrhoea were unavailable, information that would have provided an in-depth understanding on the scope of protection from $\mathrm{EBF}$ and $\mathrm{PBF}$ and the pattern of diarrhoea in the context of IYCF practices. Finally, seasonal patterns exist for diarrhoea in SSA countries (including Tanzania) [64]. However, our study was limited to calendar years. Using monthly data would have provided better and detailed findings.

Despite the limitations, the study has strengths. First, we believe that the potential impact of selection bias is unlikely to affect the study findings given the nationally representative sample of participants and the subsequent response rate (96\%). Second, the study used the TDHS data, which were collected with standardised questionnaires to ensure similarities across geographies in Tanzania. Finally, the study provides additional evidence on the impact of optimal IYCF practices on diarrhoea-the second most common cause of deaths among children under 5 years-to continue the advocacy for interventions that seek to promote child survival.

\section{Conclusion}

The study found that diarrhoea prevalence was higher among children whose mothers practised suboptimal IYCF in Tanzania. EBF and PBF were protective against diarrhoeal illness, while the introduction of solid, semisolid and soft foods to infants aged 6-8 months was associated with an increased onset of diarrhoea in Tanzanian children. Strengthening facility (e.g. BFHI and postnatal care follow-up)- and community (e.g. BFCI)-based linkages would help to improve IYCF and reduce under-five mortality from diarrhoea in Tanzanian children.

\section{Abbreviations}

BFCl: Baby-Friendly Community Initiative; BFHI: Baby-Friendly Hospital Initiative; EBF: Exclusive breastfeeding; IYCF: Infant and young child feeding;
PBF: Predominant breastfeeding; TDHS: Tanzania demographic and health survey; WHO: World Health Organization

Acknowledgements

The authors are grateful to Measure DHS, ICF International, Rockville, Maryland, USA, for providing the data for the analysis.

\section{Funding}

This study received no specific grant from any funding agency in public, commercial or not-for-profit sectors.

\section{Availability of data and materials}

The analysis was based on the datasets collected for the Tanzania Demographic and Health Survey. Information on the data and content can be assessed at http://www.dhsprogram.com/data/available-datasets.cfm.

\section{Authors' contributions}

FAO contributed to the conceptualisation of the study, drafted the manuscript, interpreted the results and critically revised the manuscript as submitted. HN contributed to the conceptualisation of the research idea, obtained the data and analysed and interpreted the results. AP contributed to the conceptualisation of the study, analyses and interpretation of the data and critically revised the manuscript. SN interpreted the results and critically revised the manuscript. KEA contributed to the data analyses and data interpretation and critically revised the manuscript. All authors read and approved the final manuscript as submitted.

\section{Ethics approval and consent to participate}

Measured DHS/ICF International obtained ethical approval from the Medical Research Coordinating Committee (MRCC), the national health research coordinating body in Tanzania. All questionnaires used for the DHS were reviewed and approved by ICF International Institutional Review Board (IRB) to ensure they met the US Department of Health and Human Services regulations for the protection of human participants as well as the host country's IRB, to ensure compliance with national laws. The datasets used are available to apply for online, and approval was obtained from Measured DHS/ICF International for the analysis.

Consent for publication

Not applicable.

\section{Competing interests}

The authors declare that they have no competing interests.

\section{Publisher's Note}

Springer Nature remains neutral with regard to jurisdictional claims in published maps and institutional affiliations.

Received: 16 November 2017 Accepted: 22 January 2018

Published online: 30 January 2018

\section{References}

1. Black MM, Walker SP, Fernald LC, Andersen CT, DiGirolamo AM, Lu C, et al. Early childhood development coming of age: science through the life course. Lancet. 2017;389(10064):77-90.

2. Chan M, Lake A, Hansen $\mathrm{K}$. The early years: silent emergency or unique opportunity? Lancet. 2017;389(10064):11-3.

3. Wang H, Bhutta AZ, Coates MM, Coggeshall M, Dandona L, Diallo K, et al. Global, regional, national, and selected subnational levels of stillbirths, neonatal, infant, and under-5 mortality during 1980-2015: a systematic analysis for the Global Burden of Disease Study 2015. Lancet. 2016;388: 1725-74.

4. GBD Diarrhoeal Diseases Collaborators. Estimates of global, regional, and national morbidity, mortality, and aetiologies of diarrhoeal diseases: a systematic analysis for the Global Burden of Disease Study 2015. Lancet Infect Dis. 2017;S1473-3099(17):30336-5

5. Victora CG, Bahl R, Barros AJ, França GV, Horton S, Krasevec J, et al. Breastfeeding in the 21st century: epidemiology, mechanisms, and lifelong effect. Lancet. 2016:387(10017):475-90.

6. Lamberti LM, Walker C, Fischer L, Noiman A, Victora C, Black RE. Breastfeeding and the risk for diarrhea morbidity and mortality. BMC Public Health. 2011;11(Suppl 3):S15 
7. Mihrshahi S, Oddy WH, Peat JK, Kabir I. Association between infant feeding patterns and diarrhoeal and respiratory illness: a cohort study in Chittagong, Bangladesh. Int Breastfeed J. 2008;3(1):23-8.

8. UNICEF, WHO. Pneumonia and diarrhoea: tackling the deadliest diseases for the world's poorest children. New York: UNICEF; 2012.

9. Ahs JW, Tao W, Löfgren J, Forsberg BC. Diarrheal diseases in low- and middle-income countries: incidence, prevention and management. Open Infect Dis J. 2010;4(1):113-24.

10. Ogbo FA, Page A, Idoko J, Claudio F, Agho KE. Diarrhoea and suboptimal feeding practices in Nigeria: evidence from the national household surveys. Paediatr Perinat Epidemiol. 2016:30:346-55.

11. Rajiv B, Frost C, Kirkwood BR, Edmon K, Martines J, Bhandari N, Arthur P. Infant feeding patterns and risks of death and hospitalization in the first half of infancy: multicentre cohort study. Bull World Health Organ. 2005;83(6):418-26.

12. Horta BL, Loret de Mola C, Victora CG. Long-term consequences of breastfeeding on cholesterol, obesity, systolic blood pressure and type 2 diabetes: a systematic review and meta-analysis. Acta Paediatr. 2015:104(S467):30-7.

13. Ogbo FA, Eastwood J, Page A, Arora A, McKenzie A, Jalaludin B, et al. Prevalence and determinants of cessation of exclusive breastfeeding in the early postnatal period in Sydney. Aust Int Breastfeed J. 2017;12(1):16.

14. Sheth M, Dwivedi R. Complementary foods associated diarrhea. Indian J Pediatr. 2006;73(1):61-4.

15. Sheth M, Obrah M. Diarrhea prevention through food safety education. Indian J Pediatr. 2004;71(10):879-82.

16. Ogbo FA, Page A, Idoko J, Claudio F, Agho KE. Trends in complementary feeding indicators in Nigeria, 2003-2013. BMJ Open. 2015;5(10):e008467.

17. Scrimshaw NS, SanGiovanni JP. Synergism of nutrition, infection, and immunity: an overview. Am J Clin Nutr. 1997;66(2):464S-77S.

18. Victor R, Baines SK, Agho KE, Dibley MJ. Determinants of breastfeeding indicators among children less than 24 months of age in Tanzania: a secondary analysis of the 2010 Tanzania Demographic and Health Survey. BMJ Open. 2013;3(1): e001529. https://doi.org/10.1136/bmjopen-2012-001529.

19. National Bureau of Statistics (NBS) [Tanzania] and ICF Macro. Tanzania demographic and health survey 2010. Dar es Salaam: NBS and ICF Macro; 2011.

20. Haidong W, Amanuel AA, Kalkidan HA, Cristiana A, Kaja MA, Foad A-A, et al. Global, regional, and national under-5 mortality, adult mortality, age-specific mortality, and life expectancy, 1970-2016: a systematic analysis for the Global Burden of Disease Study 2016. Lancet. 2017;390:1084-150.

21. Hay IS, Abajobir AA, Abate KH, Abbafati C, Abbas KM, Abd-Allah F, et al. Global, regional, and national disability-adjusted life-years (DALYs) for 333 diseases and injuries and healthy life expectancy (HALE) for 195 countries and territories, 1990-2016: a systematic analysis for the Global Burden of Disease Study 2016. Lancet. 2017;390(10100):1260-344.

22. Mashoto KO, Malebo HM, Msisiri E, Peter E. Prevalence, one week incidence and knowledge on causes of diarrhea: household survey of under-fives and adults in Mkuranga district, Tanzania. BMC Public Health. 2014;14(1):985.

23. Ministry of Health Community Development Gender Elderly and Children (MoHCDGEC) [Tanzania Mainland], Ministry of Health $(\mathrm{MoH})$ [Zanzibar], National Bureau of Statistics (NBS), Office of the Chief Government Statistician (OCGS), ICF. Tanzania Demographic and Health Survey and Malaria Indicator Survey (TDHS-MIS). Dar es Salaam, Tanzania and Rockville, Maryland, USA: NBS and ICF International, 2016.

24. Hajeebhoy N, Nguyen H, Mannava P, Nguyen TT, Tran ML. Suboptima breastfeeding practices are associated with infant illness in Vietnam. Int Breastfeed J. 2014:9:12

25. Ogbo FA, Agho K, Ogeleka P, Woolfenden S, Page A, Eastwood J. Infant feeding practices and diarrhoea in sub-Saharan African countries with high diarrhoea mortality. PLoS One. 2017;12(2):e0171792.

26. Kamenju P, Liu E, Hertzmark E, Spiegelman D, Kisenge RR, Kupka R, et al. Complementary feeding and diarrhea and respiratory infection among HIVexposed Tanzanian infants. JAIDS. 2017;74(3):265-72.

27. Mwiru RS, Spiegelman D, Duggan C, Peterson K, Liu E, Msamanga G, et al. Relationship of exclusive breast-feeding to infections and growth of Tanzanian children born to HIV-infected women. Public Health Nutr. 2011;14(7):1251-8

28. Lee B, Dutta A, Lyimo H, Silaa R, Futures Group and Health Policy Project. Budget analysis of the govenrment of Tanzania's Ministry of Health and Social Welfare, fiscal year 2015/2016. Washington, DC: Health Policy Project; 2015.

29. United Nations General Assembly. The UN Decade of Action on Nutrition: working together to implement the outcomes of the Second International Conference on Nutrition. New York: United Nations; 2016.
30. The Demographic and Health Survey Program. Publications by country Online2016. Available from: https://dhsprogram.com/Publications/ Publications-by-Country.cfm. Accessed 26 Sept 2017.

31. Agho KE, Ogeleka P, Ogbo FA, Ezeh OK, Eastwood J, Page A. Trends and predictors of prelacteal feeding practices in Nigeria (2003-2013). Nutrients. 2016;8(8):462.

32. World Health Organization. Indicators for assessing infant and young child feeding practices. Geneva: World Health Organization; 2008.

33. Ladomenou F, Moschandreas J, Kafatos A, Tselentis Y, Galanakis E. Protective effect of exclusive breastfeeding against infections during infancy: a prospective study. Arch Dis Child. 2010;95(12):1004-8.

34. Black RE, Victora CG, Walker SP, Bhutta ZA, Christian P, de Onis M, et al. Maternal and child undernutrition and overweight in low-income and middle-income countries. Lancet 2013;382(9890):427-451. doi: https://doi. org/10.1016/S0140-6736(13)60937-X. PubMed PMID: 23746772.

35. World Health Organization. WHO collaborative study team on the role of breastfeeding on the prevention of infant mortality effect of breastfeeding on infant and child mortality due to infectious diseases in less developed countries: a pooled analysis. Lancet. 2000;355(9202):451-5.

36. World Health Organisation. The global strategy for infant and young child feeding. Geneva: WHO; 2003

37. World Health Organization. Indicators for accessing breastfeeding practices. Geneva: World Health Organization; 1991

38. World Health Organisation, United Nations Children Education Fund. Core questions and indicators for monitoring WASH in Schools in the Sustainable Development Goals. United States of America: WHO \& UNICEF, 2016.

39. Turfkruyer $M$, Verhasselt $V$. Breast milk and its impact on maturation of the neonatal immune system. Curr Opin Infect Dis. 2015;28(3):199-206.

40. Cederlund A, Kai-Larsen Y, Printz G, Yoshio H, Alvelius G, Lagercrantz H, et al. Lactose in human breast milk an inducer of innate immunity with implications for a role in intestinal homeostasis. PLoS One. 2013;8(1):e53876.

41. Verduci E, Banderali G, Barberi S, Radaelli G, Lops A, Betti F, et al. Epigenetic effects of human breast milk. Nutrients. 2014;6(4):1711-24.

42. Acharya D, Singh JK, Adhikari M, Gautam S, Pandey P, Dayal V. Association of water handling and child feeding practice with childhood diarrhoea in rural community of Southern Nepal. J Infect Public Health. 2017;S18760341(17):30136-3

43. Santos FS, Santos LH, Saldan PC, Santos FC, Leite AM, Mello DF. Breastfeeding and acute diarrhoea among children enrolled in the family health strategy. Texto Contexto-Enfermagem. 2016;25(1):e0220015.

44. Popkin BM, Adair L, Akin JS, Black R, Briscoe J, Flieger W. Breast-feeding and diarrheal morbidity. Pediatrics. 1990;86(6):874-82.

45. Agunbiade OM, Ogunleye OV. Constraints to exclusive breastfeeding practice among breastfeeding mothers in Southwest Nigeria: implications for scaling up. Int Breastfeed J. 2012;7:5. https://doi.org/10.1186/1746-4358-7-5.

46. Bezner Kerr RDL, Shumba L, et al. "We grandmothers know plenty": breastfeeding, complementary feeding and the multifaceted role of grandmothers in Malawi. Soc Sci Med. 2008;66:1095-105

47. Agho K, Dibley M, Odiase J, Ogbonmwan S. Determinants of exclusive breastfeeding in Nigeria. BMC Pregnancy Childbirth. 2011;11:2.

48. United Nations Childen's Fund. Tanzania overview 2017 [cited 20172 October ]. Available from: https://www.unicef.org/tanzania/.

49. Fuchs SC, Victora CG, Martines J. Case-control study of risk of dehydrating diarrhoea in infants in vulnerable period after full weaning. BMJ. 1996; 313(7054):391-4.

50. Käferstein F. Food safety: the fourth pillar in the strategy to prevent infant diarrhoea. Bull World Health Organ. 2003;81(11):842-3.

51. Kimanya ME, Meulenaer B, Camp J, Baert K, Kolsteren P. Strategies to reduce exposure of fumonisins from complementary foods in rural Tanzania. Matern Child Nutr. 2012:8(4):503-11.

52. Shabani I, Kimanya ME, Gichuhi PN, Bonsi C, Bovell-Benjamin AC. Maize storage and consumption practices of farmers in Handeni District, Tanzania: corollaries for mycotoxin contamination. Open J Prev Med. 2015;5(08):330.

53. Kimanya ME, De Meulenaer B, Roberfroid D, Lachat C, Kolsteren P. Fumonisin exposure through maize in complementary foods is inversely associated with linear growth of infants in Tanzania. Mol Nutr Food Res. 2010;54(11):1659-67.

54. Jolly $P$, Jiang $Y$, Ellis W, Awuah $R$, Nnedu O, Phillips T, et al. Determinants of aflatoxin levels in Ghanaians: sociodemographic factors, knowledge of aflatoxin and food handling and consumption practices. Int J Hyg Environ Health. 2006;209(4):345-58. 
55. Kimanya ME, De Meulenaer B, Tiisekwa B, Ndomondo-Sigonda M, Devlieghere F, Van Camp J, et al. Co-occurrence of fumonisins with aflatoxins in home-stored maize for human consumption in rural villages of Tanzania. Food Addit Contam. 2008:25(11):1353-64.

56. Ministry of Health -Tanzania. The World Breastfeeding Trends Initiative (WBTi)_Tanzania. Tanzania: Ministry of Health; 2015.

57. Caldeira AP, Gonçalves E. Assessment of the impact of implementing the Baby-Friendly Hospital Initiative. J Pediatr. 2007;83(2):127-32.

58. Khan M, Akram DS. Effects of baby-friendly hospital initiative on breastfeeding practices in sindh. Parity. 2013;4(40):34.

59. Venancio SI, Saldiva SRDM, Escuder MML, Giugliani ERJ. The Baby-Friendly Hospital Initiative shows positive effects on breastfeeding indicators in Brazil. J Epidemiol Community Health. 2012;66(10):914-8.

60. Abrahams SW, Labbok MH. Exploring the impact of the Baby-Friendly Hospital Initiative on trends in exclusive breastfeeding. Int Breastfeed J. 2009;4(1):1.

61. Ogunlesi TA, Dedeke O, Okeniyi J, Oyedeji G. Infant And Toddler Feeding Practices In The Baby Friendly Initiative (BFI) Era In llesa, Nigeria. Internet J Nutr Wellness. 2004;1(2):1-5.

62. United Republic of Tanzania. Tanzania National Multisectoral Nutrition Action Plan (NMNAP) for the period July 2016 - June 2021: STRATEGIC PLAN: From Evidence to Policy to Action. Dar Es Salaam: Prime Minister's Office, 2016 July 2016. Report No.

63. Enzama W, Afidra R, Johnson Q, Verster A. Africa maize fortification strategy 2017-2026. Online: Smarter Futures, 2017.

64. Bandyopadhyay S, Kanji S, Wang L. The impact of rainfall and temperature variation on diarrheal prevalence in Sub-Saharan Africa. Appl Geogr. 2012:33:63-72.

\section{Submit your next manuscript to BioMed Central and we will help you at every step:}

- We accept pre-submission inquiries

- Our selector tool helps you to find the most relevant journal

- We provide round the clock customer support

- Convenient online submission

- Thorough peer review

- Inclusion in PubMed and all major indexing services

- Maximum visibility for your research

Submit your manuscript at www.biomedcentral.com/submit 